\title{
Caenorhabditis elegans gcs-1 confers resistance to arsenic-induced oxidative stress
}

\author{
Vivian Hsiu-Chuan Liao* \& Chan-Wei Yu \\ Department of Bioenvironmental Systems Engineering, National Taiwan University, No. 1, Sec. 4, Roosevelt \\ Road, Taipei, 106, Taiwan; *Author for correspondence (Tel: +886-2-3366-5239; Fax: + 886-2-3366-3462; \\ E-mail: vivianliao@ntu.edu.tw)
}

Received 16 June 2005; accepted 7 September 2005

Key words: gamma-glutamylcysteine synthetase, glutathione, Caenorhabditis elegans, arsenic

\begin{abstract}
Gamma-glutamylcysteine synthetase $(\gamma$-GCS) catalyzes the first, rate-limiting step in the biosynthesis of glutathione (GSH). To evaluate the protective role of cellular GSH against arsenic-induced oxidative stress in Caenorhabditis elegans (C. elegans), we examined the effect of the C. elegans ortholog of GCS(h), gcs-1, in response to inorganic arsenic exposure. We have evaluated the responses of wild-type and $g c s-1$ mutant nematodes to both inorganic arsenite $(\mathrm{As}(\mathrm{III}))$ and arsenate $(\mathrm{As}(\mathrm{V}))$ ions and found that gcs-1 mutant nematodes are more sensitive to arsenic toxicity than that of wild-type animals. The amount of metal ion required to kill half of the population of worms falls in the order of wild-type $/ \mathrm{As}(\mathrm{V})>g \operatorname{cs}-1 / \mathrm{As}(\mathrm{V})>$ wildtype/As(III) $>g c s-1 / \mathrm{As}(\mathrm{III})$. $g c s-1$ mutant nematodes also showed an earlier response to the exposure of $\mathrm{As}(\mathrm{III})$ and $\mathrm{As}(\mathrm{V})$ than that of wild-type animals. Pretreatment with GSH significantly raised the survival rate of $g c s-1$ mutant worms compared to As(III)- or As(V)-treated worms alone. These results indicate that GCS-1 is essential for the synthesis of intracellular GSH in C. elegans and consequently that the intracellular GSH status plays a critical role in protection of $C$. elegans from arsenic-induced oxidative stress.
\end{abstract}

\section{Introduction}

Arsenic is an environmental chemical of toxicological concern. It is a naturally occurring element, but anthropogenic activities can lead to substantial contamination of the environment. Arsenic, a known human carcinogen, is widely distributed in food, water, soil, and air. It was ranked first on The Comprehensive Environmental Response, Compensation, and Liability Act (CERCLA) priority list of hazardous substances in 2003 (http:// www.atsdr.cdc.gov/clist.html). Arsenic is introduced into water through the dissolution of minerals and ores. In addition, arsenic can accumulate in groundwater and well water in some areas as a result of erosion or leaching from local rocks. Moreover, industrial effluents, combustion of fossil fuels, and arsenic pesticides all contribute to arsenic contamination in freshwater systems (Tchounwou et al. 1999). Exposure to arsenic in drinking water represents a significant health problem for people around the world. Epidemiologic studies in Taiwan, Chile, Bangaldesh, and India have shown that arsenic exposure is associated with skin, liver, lung, bladder, and other cancers (Abernathy et al. 1999; NRC 1999; ATSDR 2000).

The toxicological effects of arsenic highly depend on its oxidation state, chemical composition, and bioavailability (Lerman et al. 1983). The trivalent form of arsenic appears to be the most toxic regardless of whether it is in an inorganic or organic form (Del Razo et al. 2001). The exact mechanism(s) of cellular and molecular events associated with arsenic toxicity are not well understood. While inorganic arsenic is known to be a human carcinogen, the precise mechanisms by which arsenic acts as a carcinogen in humans remain to be elucidated. 
Oxidative stress results from an imbalance between free radical generation and the antioxidant defense system. Glutathione (GSH) plays a critical role in maintaining cellular redox homeostasis. GSH is also an important intracellular molecule that protects cells against endogenous and exogenous oxidative stress. Depletion of GSH by oxidants, for example, may alter the redox status of the cell and present a stressful and toxic situation. GSH levels have been reported to decrease, to increase or to remain unchanged after exposure to different metals (Eaton et al. 1980; Dudley \& Klaassen 1984; Canesi et al. 1998). Arsenic exposure appears to induce oxidative stress and has been shown to affect intracellular GSH status in a number of cells (Ochi 1997). A primary target of arsenic is GSH (Cavigelli et al. 1996) and marked changes in GSH levels following arsenic exposure are commonly observed. Depletion of intracellular GSH in arsenite exposed cells was known to induce growth inhibition, apoptosis (Dai et al. 1999) and cytotoxicity (Shimizu et al. 1998). Moreover, studies in cultured BALB/c 3T3 cells (Ochi et al. 1994) and human fibroblasts (OyaOhta et al. 1996) showed that intracellular GSH plays an important role in the detoxification machinery against arsenite toxicity. These studies suggested that an increase in cellular oxidative stress could be one of the underlying mechanisms in arsenite-induced toxicity.

Glutathione is synthesized in the cell cytosol by $\gamma$-glutamylcysteine synthetase (GCS) and glutathione synthetase (Meister \& Anderson 1983). GCS is proposed to catalyze the first and ratelimiting step in GSH biosynthesis (Richman \& Meister 1975). Factors that regulate the expression and activity of GCS are therefore of considerable interest, as GCS appears to play a principal role in modulating glutathione homeostasis and consequently affects the capacity of the cell to withstand the deleterious effects of oxidative stress. Several studies have shown that intracellular GSH plays a principal role in protecting cells from arsenite-induced cytotoxicity in vitro (Huang et al. 1993; Ochi et al. 1994) and in vivo (Hirata et al. 1990). However, the role of intracellular GSH and GCS in related to arsenite-induced toxicity has not been studied in the nematode $C$. elegans yet.

cDNA clones encoding GCS have been isolated from several different eukaryotic and prokaryotic sources. In mammals, GCS is a heterodimer comprising a catalytic heavy subunit $(73 \mathrm{kDa}$, GCS(h)) and a regulatory light subunit (30 kDa, GCS(1)) (Hayes \& McLellan 1999). In C. elegans, the predicted gene, gcs- 1 is the $C$. elegans ortholog of GCS(h), a representative and well-characterized transcription factor $\mathrm{Nrf}$ target gene (Hayes \& McMahon 2001). Recently, it has been shown that gcs-1 expression in the intestine of C. elegans is induced by the transcription factor SKN-1 in response to paraquat-induced oxidative stress. (An \& Blackwell 2003).

Because arsenic plays an important role in oxidative stress in biological systems, we were interested in whether arsenic-induced oxidative stress was influenced by GSH synthesis in C. elegans. $C$. elegans provides an excellent model system for obtaining an integrated picture of cellular, developmental, and molecular aspects of metal and metalloid toxicity (Liao \& Freedman 2002). The adult hermaphrodite is composed of 959 somatic cells. The developmental and cellular biology of $C$. elegans is thoroughly understood, and the nematode contains highly differentiated muscular, nervous, digestive, and reproductive systems. Furthermore, high levels of evolutionary conservation between $C$. elegans and higher organisms are observed in many of the proteins that are induced as part of a metal-activated stress response. These include metallothione (Freedman et al. 1993), superoxide dismutase (Giglio et al. 1994), ubiquitin (Stringham et al. 1992), heat shock protein 70 (Heschl et al. 1990), glutathione $S$-transferase (Tawe et al. 1998), catalase (Sampayo et al. 2003), multidrug resistance-associated proteins (Broeks et al. 1996), and cadmium-responsive genes (Liao \& Freedman 1998; Liao \& Freedman 2001; Liao et al. 2002). C. elegans also contains homologues to many of the regulatory proteins that have been implicated in modulating the molecular response to metal exposure (Land et al. 1994; Kawasaki et al. 1999).

To evaluate the protective role of cellular GSH against the toxicity of arsenic in C. elegans, the effect of $g c s-1$ responding to inorganic arsenic exposure was investigated. We have examined responses of C. elegans to both inorganic As(III) and $\mathrm{As}(\mathrm{V})$ ions as they have been implicated in the generation of reactive oxygen species (ROS) and subsequent damage to proteins and DNA. We hypothesize that inorganic arsenic exposure can disturb intracellular GSH status and hence result 
in toxicity in C. elegans. We also hypothesize that C. elegans gcs- 1 plays a critical role in modulating GSH homeostasis and consequently the ability of the cell to withstand the deleterious effects of arsenic-induced oxidative stress. The toxic response of $C$. elegans to the different oxidation states of arsenic was also compared.

\section{Materials and methods}

\section{Chemicals}

Unless otherwise stated, all chemicals were purchased from Sigma Chemical (St. Louis, MO, USA).

\section{Nematode propagation and strains}

Caenorhabditis elegans were grown in Petri dishes on nematode growth medium (NGM) and fed with OP50 strain Escherichia coli (Brenner 1974). Synchronization of worm cultures was performed as described (Hope 1999). The following strains were used: wild-type $C$. elegans N2 (var. Bristol); gcs-1 mutant: VC337 [gcs-1(ok436)/mIn1/mIs14 dpy$10(\mathrm{e} 128)]$ which is a $837 \mathrm{bp}$ chromosomal deletion (ok436) of the $g c s-1$ locus. All nematode strains used in this work were provided by the Caenorhabditis Genetics Center (University of Minnesota), which is funded by the NIH National Center for Research Resources (NCRR).

\section{Intracellular GSH measurement}

To measure intracellular GSH content in the wildtype and the $g c s-1$ mutant, GSH assay was performed. One hundred and twenty young adult hermaphrodites of wild-type (3-4 days old) or gcs-1 mutant (4-5 days old) nematodes were transferred from NGM plates into a $1.5 \mathrm{ml} \mathrm{mi-}$ crocentrifuge tube containing $300 \mu \mathrm{l}$ of lysis buffer (100 mM sodium phosphate buffer, $1 \mathrm{mM}$ EDTA, $\mathrm{pH}$ 7.5). Worms were sonicated, then centrifuged at $10,000 \times g$ for $10 \mathrm{~min}$. The supernatant was collected, and 5-sulfosalycyclic acid (SSA) was added to a final concentration of $1 \%$ SSA. The mixture was then centrifuged at $10,000 \times g$ for $10 \mathrm{~min}$, and the supernatant was then collected for use in the assay. For GSH measurements, $50 \mu \mathrm{l}$ aliquots of each sample were placed in a 96-well plate with $150 \mu$ l reaction buffer $\left(100 \mathrm{mM} \mathrm{NaH}_{2}\right.$ $\mathrm{PO}_{4}, 1 \mathrm{mM}$ EDTA (pH 7.5), $0.15 \mathrm{mM}$ DTNB, $0.2 \mathrm{mM}$ NADPH, $1 \mathrm{U} / \mathrm{ml}$ glutathione reductase). The rate of absorbance change of the samples was measured at $405 \mathrm{~nm}$ at $25^{\circ} \mathrm{C}$ over $2 \mathrm{~min}$. Concentrations of total GSH of the sample were determined using standard curves of GSH.

\section{Arsenic toxicity analyses}

Twenty young adult hermaphrodites of wild-type or gcs-1 mutant nematodes were transferred from NGM plates into a Costar 24-well tissue culture plates containing $1 \mathrm{ml}$ of $\mathrm{K}$ medium (53 mM $\mathrm{NaCl}, 32 \mathrm{mM} \mathrm{KCl}$ ) (Williams \& Dusenbery 1990) with various concentrations of $\mathrm{As}(\mathrm{III})$ or $\mathrm{As}(\mathrm{V})$ per well. Wild-type animals were exposed to $0,0.5$, $1.5,3.0$, and $4.5 \mathrm{mM}$ nominal concentration of As(III) or $0,10,20,40,50$, and $60 \mathrm{mM}$ of $\mathrm{As}(\mathrm{V})$. The exposure nominal concentration for $\mathrm{gcs}-1$ mutant nematodes were $0,0.025,0.05,0.075$, and $0.1 \mathrm{mM}$ of $\mathrm{As}(\mathrm{III})$ or $0,1.5,3.0,6.0$, and $9.0 \mathrm{mM}$ of $\mathrm{As}(\mathrm{V})$. Worms were incubated at $20{ }^{\circ} \mathrm{C}$ and the dead worms were scored at different time points ranging from 2 - to 24 -h $( \pm 10 \mathrm{~min})$. The number of dead worms was determined by the absence of touch-provoked movement when probed with a platinum wire. The tests were performed between three and six times for each concentration.

\section{GSH rescue assay}

Young adult hermaphrodites of gcs- 1 mutant nematodes were pretreated with or without $50 \mu \mathrm{M}$ $\mathrm{GSH}$ in $\mathrm{K}$ medium for $3 \mathrm{~h}$. Worms were washed twice with $\mathrm{K}$ medium and then transferred back to NGM plates. Subsequently 20 animals from each treatment were transferred from NGM plates into Costar 24-well tissue culture plates containing $1 \mathrm{ml}$ of $\mathrm{K}$ medium per well with various concentrations of $\mathrm{As}(\mathrm{III})$ or $\mathrm{As}(\mathrm{V})$. Worms were incubated at $20{ }^{\circ} \mathrm{C}$ and the dead worms were scored after $24 \mathrm{~h}( \pm 10 \mathrm{~min})$. The number of dead worms was determined as described above. The tests were performed between three and six times.

\section{Data analysis}

The lethal concentration $\left(\mathrm{LC}_{50}\right)$ from the toxicity assays was determined using a Probit transformation (USEPA). The experiments were 
performed between three and six times for error analyses. The data were used to calculate the standard deviations. Significant differences between the data were determined using student's $t$-test. With the exception of the Probit transformations, all analyses were performed using Statistaca software (StatSoft, Tulsa, OK, USA).

\section{Results}

\section{Intracellular GSH measurement}

To determine whether $g c s-1$ plays a critical role in modulating GSH homeostasis in C. elegans, intracellular GSH was measured in wild-type and gcs-1 mutant nematodes. As shown in Figure 1, intracellular GSH content in gcs-1 mutant $(0.767 \pm 0.152 \mathrm{nmol} / 120$ worms $)$ was significantly $(P<0.001)$ lower than the value of the wild-type $(1.139 \pm 0.189 \mathrm{nmol} / 120$ worms $)$. This is in agreement with our hypothesis that $g c s-1$ regulates the synthesis of GSH in C. elegans.

\section{Lethality tests of $A s(I I I)$ and $A s(V)$ and establishment of LC value}

To investigate the ability of C. elegans to withstand the arsenic-induced toxicity, wild-type and $g c s-1$ mutant nematodes were exposed to a range of As(III) and As (V) ion concentrations and the dead worms were scored over a $24 \mathrm{~h}$ period. The proportion of worms surviving As(III) concentrations

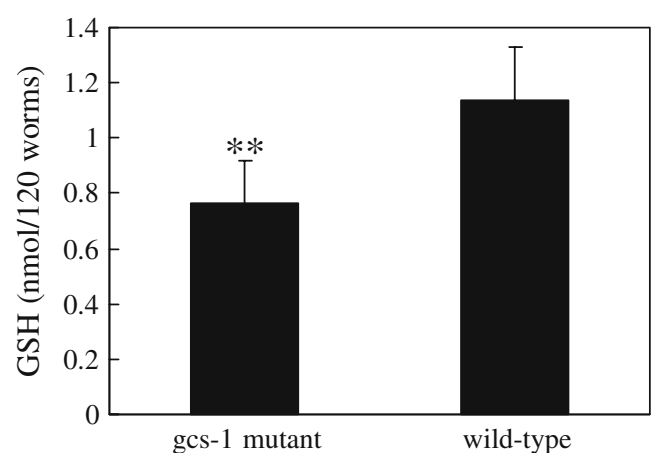

Figure 1. Intracellular GSH measurement. Intracellular GSH content was measured in 120 young adult hermaphrodites of wild-type or $g c s-1$ mutant nematodes as described in Materials and methods. Here, we employed GSH concentrations to represent intracellular glutathione concentrations. The data are represented as means $\pm \mathrm{SD}, n=4$. **indicates $P<0.001$. from 0.025 to $4.5 \mathrm{mM}$ after $24 \mathrm{~h}$ exposure varied considerably between strains (Figure 2a). The As(III) LC $_{50}$ value for $g c s-1$ mutant $(0.085 \pm$ $0.019 \mathrm{mM})$ was significantly $(P<0.01)$ lower than the value of the wild-type $(1.282 \pm 0.306 \mathrm{mM})$ (Figure 2b).

Similarly, gcs-1 mutant was less resistant to $\mathrm{As}(\mathrm{V})$ ions than the wild-type strain. The proportion of worms surviving $\mathrm{As}(\mathrm{V})$ concentrations from 1.5 to $60.0 \mathrm{mM}$ after $24 \mathrm{~h}$ exposure varied considerably between strains (Figure 3a). The $\mathrm{As}(\mathrm{V}) \mathrm{LC}_{50}$ value for the $g c s-1$ mutant $(2.780 \pm$ $0.563 \mathrm{mM})$ was significantly $(P<0.001)$ lower than the $\mathrm{LC}_{50}$ value of the wild-type (34.54 $3.261 \mathrm{mM}$ ) (Figure 3b). As(III) exerts a higher toxic effect than that of $\mathrm{As}(\mathrm{V})$ to both wild-type and $g c s-1$ mutant worms. The amount of metal ion required to kill half of the population of worms falls in order of wild-type $/ \mathrm{As}(\mathrm{V})>g c s-1 / \mathrm{As}(\mathrm{V})>$ wild-type $/ \mathrm{As}(\mathrm{III})>g c s-1 / \mathrm{As}(\mathrm{III})$.

Time-dependence of $A s(I I I)$ and $A s(V)$ toxicity in C. elegans

The toxic effect of arsenic exposure to wild-type and $g c s-1$ mutant worms was investigated for time dependence. Both As(III) and As(V) induced toxicity on wild-type and gcs-1 mutant worms behaved in a time-dependent manner. The mortality rate of the nematodes to inorganic arsenic species was determined by exposing the worms to As(III) and $\mathrm{As}(\mathrm{V})$ for various time intervals as described in Materials and methods. As shown in Figure 4, the mortality rate of the wild-type worms increased as the incubation times with As(III) increased. When wild-type worms were exposed to $1.28 \mathrm{mM} \mathrm{As}(\mathrm{III})\left(\mathrm{LC}_{50}\right.$ value), the kinetic profile showed that the survival of worms was unaffected by $\mathrm{As}(\mathrm{III})$ toxicity during the first $12 \mathrm{~h}$ exposure. After $12 \mathrm{~h}$, the mortality rate of wild-type worms continuously increased until survival of worms was approximately $50 \%$ (Figure 4). Similarly, the mortality rate of the wild-type worms increased as the incubation times with $\mathrm{As}(\mathrm{V})$ increased. As shown in Figure 4, when wild-type worms were exposed to an $\mathrm{As}(\mathrm{V}) \mathrm{LC}_{50}$ value $(34.54 \mathrm{mM})$, the survival of worms was unaffected by $\operatorname{As}(\mathrm{V})$ exposure during the first $12 \mathrm{~h}$. Afterwards, the mortality rate of wild-type worms continuously increased until about $50 \%$ of the worms were dead (Figure 4). 


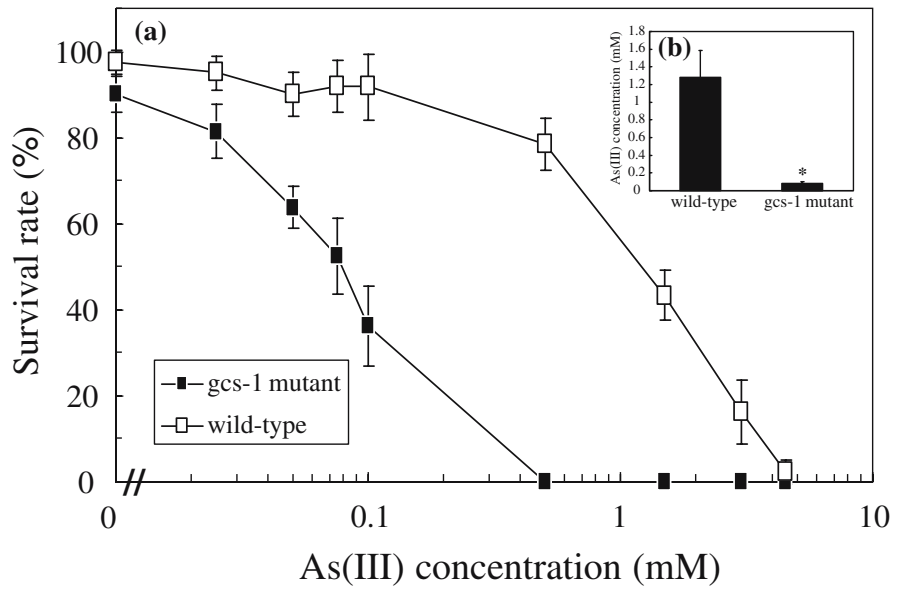

Figure 2. C. elegans As(III) toxicity assay. (a) Proportion of worms surviving a range of As(III) concentrations. Values are presented as a percentage of worms still alive at a particular metal ion concentration. (b) $24 \mathrm{~h} \mathrm{LC}_{50}$ values for $\mathrm{As}$ (III) based on the data shown in panel (a). Bars and standard errors represent concentrations of As(III) ions at which $50 \%$ of worms are recorded as dead. The data are represented as means $\pm \mathrm{SD}, n=6$. *indicates $P<0.01$.

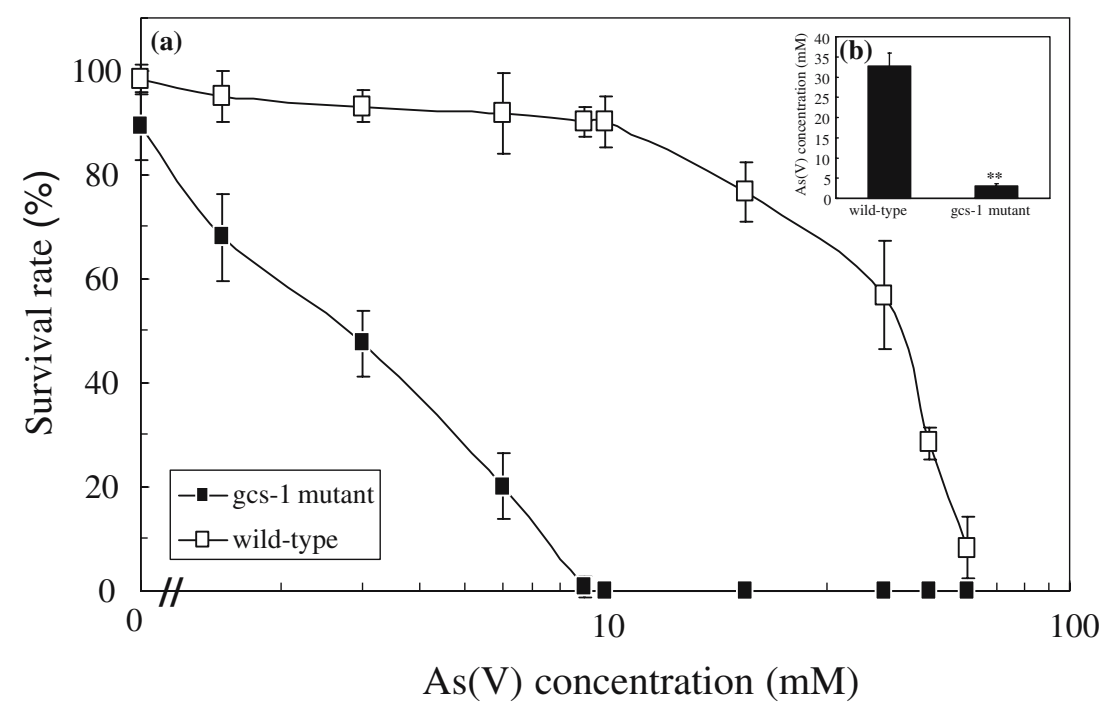

Figure 3. C. elegans $\mathrm{As}(\mathrm{V})$ toxicity assay. (a) Proportion of worms surviving a range of $\mathrm{As}(\mathrm{V})$ concentrations. Values are presented as a percentage of worms still alive at a particular metal ion concentration. (b) $24 \mathrm{~h} \mathrm{LC}_{50}$ values for As(V) based on the data shown in panel (a). Bars and standard errors represent concentrations of $\mathrm{As}(\mathrm{V})$ ions at which $50 \%$ of worms are recorded as dead. The data are represented as means $\pm \mathrm{SD}, n=6$. **indicates $P<0.001$.

The kinetic profiles of $g c s-1$ mutant exposed to As(III) and As(V) were also shown in Figure 4. The mortality rate of the $g c s-1$ mutant worms toward the exposure of these metal ions showed a time-dependence. As shown in Figure 4, the mortality rate of the $g c s-1$ mutant worms increased as the incubation times with As(III) increased. $g c s-1$ mutant worms appeared to be more susceptible to As(III) toxicity than the wildtype worms. When gcs-1 mutant worms were exposed to an $\mathrm{As}(\mathrm{III}) \mathrm{LC}_{50}$ value $(0.085 \mathrm{mM})$, the survival rate of worms began to decrease after $4 \mathrm{~h}$ exposure, and the mortality rate of nematodes continuously increased until approximately $50 \%$ of the worms were dead (Figure 4). Time-dependence of $\mathrm{As}(\mathrm{V})$-induced lethality in $g c s-1$ mutant worms was also observed. As shown in Figure 4, $\mathrm{As}(\mathrm{V})$ exposure did not result in significant lethality of the animals until $4 \mathrm{~h}$, after which the mortality rate of worms continuously increased until to approximately $50 \%$ survival of the worms were alive. 


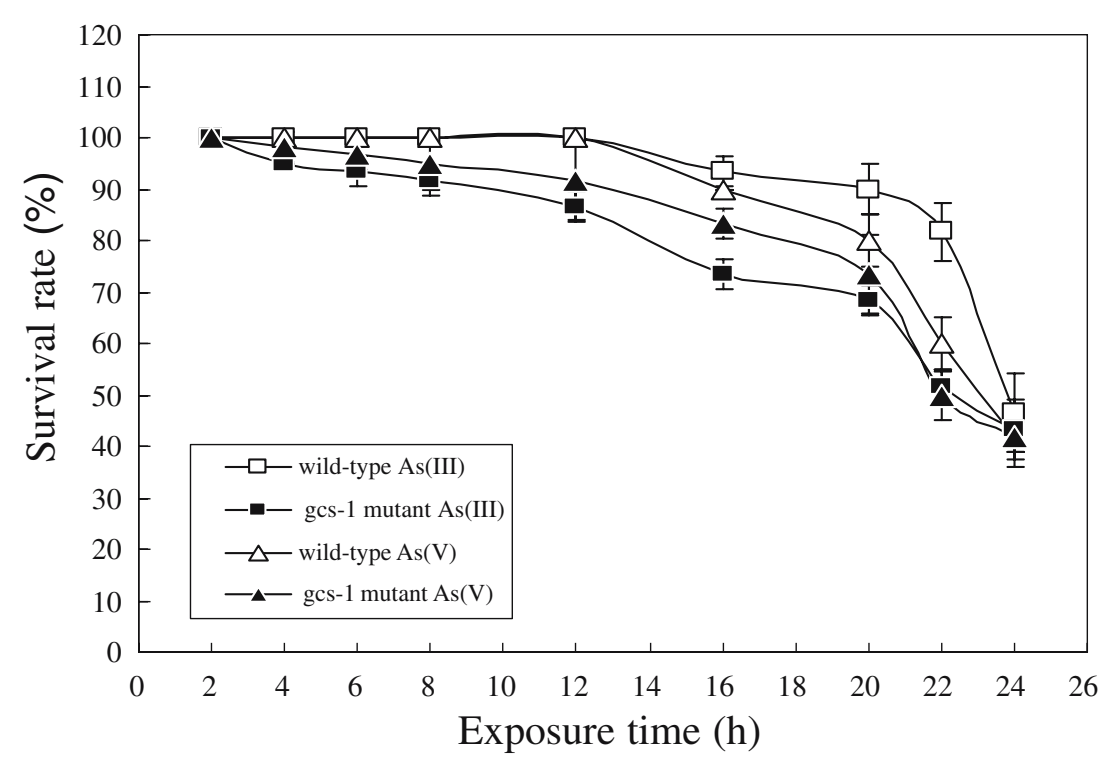

Figure 4. Time-dependent lethality of nematodes exposed to As(III) and As(V). Wild-type and gcs-1 mutant nematodes were exposed to $\mathrm{As}(\mathrm{III})$ and $\mathrm{As}(\mathrm{V})$ at its corresponding $\mathrm{LC}_{50}$. For $\mathrm{As}(\mathrm{III})$, the $\mathrm{LC}_{50}$ values for the wild-type and $g \mathrm{cs}-1$ mutant worms are 1.282 and $0.085 \mathrm{mM}$, respectively. For As(V), the $\mathrm{LC}_{50}$ values for the wild-type and gcs- 1 mutant worms are 34.540 and $2.780 \mathrm{mM}$, respectively. $\square$, wild-type worms exposed to As(III); $\mathbf{\square}, g c s-1$ mutant worms exposed to As(III); $\Delta$, wild-type worms exposed to As(V); $\mathbf{\Delta}$, gcs-1 mutant worms exposed to $\mathrm{As}(\mathrm{V})$. The data are represented as means $\pm \mathrm{SD}, n=6$.

\section{GSH rescues gcs-1 mutant}

Glutathione is the key metabolic intermediate downstream of $\gamma$-GCS. GSH was tested over a range of $50-1000 \mu \mathrm{M}$ to determine the maximum levels that worms could tolerate with normal growth. The optimal GSH concentration was $50 \mu \mathrm{M}$; concentrations above this level had detrimental effects on worm growth (data not shown). To determine whether the addition of GSH could rescue the $g c s-1$ mutant, young adult $g c s-1$ mutant worms were pretreated with or without $50 \mu \mathrm{M}$ GSH for $3 \mathrm{~h}$ and then worms were washed and exposed to various concentrations of As(III) or As(V). As shown in Figure 5, GSH rescued the lethal effect caused by the $\gamma$-GCS gene knockout. The addition of GSH significantly raised the survival rate of gcs-1 mutant worms compared to $\mathrm{As}(\mathrm{III})$ - or $\mathrm{As}(\mathrm{V})$-treated worms alone (Figure 5).

\section{Discussion}

In this paper, we demonstrate that GCS- 1 is essential for the synthesis of intracellular GSH in C. elegans and consequently that the intracellular GSH status plays a critical role in protection of
C. elegans from arsenic-induced toxicity. It is wellrecognized that intracellular GSH is an important endogenous antioxidant against the action of toxic xenobiotics (Pompella et al. 2003). Several studies have shown that intracellular GSH plays a principle role in protecting cells from arsenite-induced cytotoxicity in vitro (Huang et al. 1993; Ochi et al. 1994) and in vivo (Hirata et al. 1990). However, the role of intracellular GSH and GCS in relation to arsenite-induced toxicity has not been studied in the nematode $C$. elegans yet. Our study shows that GSH level in $g c s-1$ mutant worms was markedly lower than that of wild-type animals (Figure 1). We wished to correlate the rescue of $g c s-1$ mutant viability on medium supplemented with GSH. Pretreatment with GSH significantly raised the survival rate of $g c s-1$ mutant worms compared to $\mathrm{As}(\mathrm{III})$ - or As(V)-treated worms alone (Figure 5). Although the survival rates of the $g c s-1$ mutant worms were not restored to wild-type levels, it is notable that the survival of $C$. elegans can be restored when $g c s-1$ mutant worms were pretreated with $50 \mu \mathrm{M}$ GSH for $3 \mathrm{~h}$ (Figure 5). Therefore, the addition of GSH to medium rescued the $g c s-1$ mutant worm death phenotype providing further evidence that GSH is an essential metabolite in these animals. 

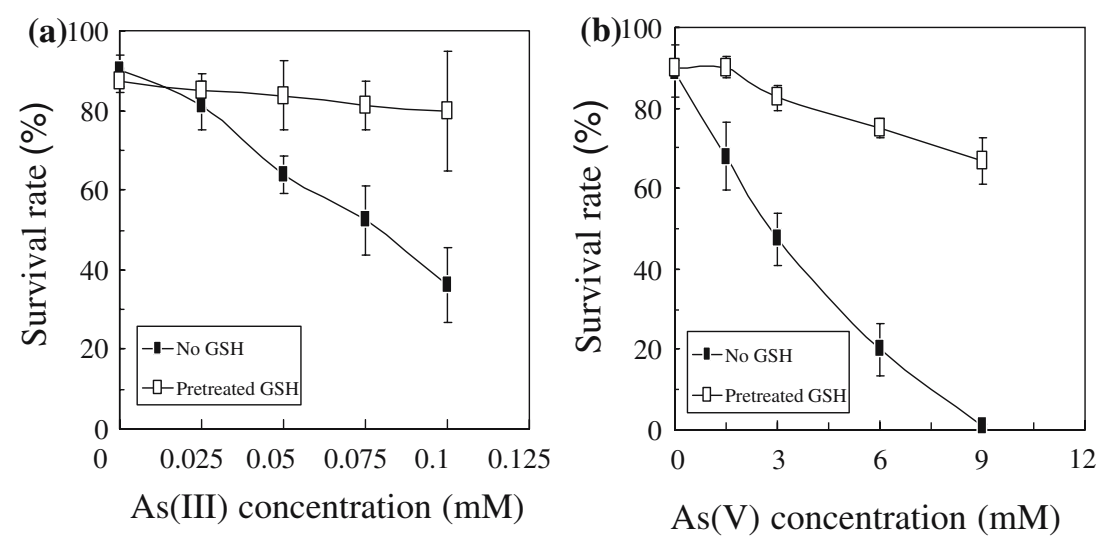

Figure 5. GSH rescue assay. gcs-1 mutant nematodes were pretreated with or without $50 \mu \mathrm{M}$ GSH for $3 \mathrm{~h}$ and then worms were washed and exposed to various concentrations of As(III) or As(V). Worms were incubated at $20{ }^{\circ} \mathrm{C}$ and the dead worms were scored over a $24 \mathrm{~h}$ period. The number of dead worms was determined as described in Materials and methods. (a) Proportion of gcs-1 mutant worms surviving a range of As(III) concentrations with or without GSH pretreatment. (b) Proportion of $g c s-1$ mutant worms surviving a range of $\mathrm{As}(\mathrm{V})$ concentrations with or without $\mathrm{GSH}$ pretreatment. The data are represented as means $\pm \mathrm{SD}, n=6$.

Moreover, our data show that the extent of the rescue by GSH pretreatment is the same range for both $\mathrm{As}(\mathrm{III})$ and $\mathrm{As}(\mathrm{V})$ even the toxicity of both substances differs dramatically. This suggests that $\mathrm{As}(\mathrm{V})$ was reduced to $\mathrm{As}(\mathrm{III})$ in the presence of GSH in C. elegans. GSH has been shown to serve as an electron donor for the reduction of $\mathrm{AS}(\mathrm{V})$ to As(III) in aqueous solutions and in erythrocytes (Scott et al. 1993; Delnomdedieu et al. 1994). In addition, the reduction of As to trivalency by GSH has been shown to be linked to the formation of arsenotriglutathione (As(III) (GS) ${ }_{3}$ ) (Delnomdedieu et al. 1993). The reduction of As(V) to As(III) may also be catalyzed by $\mathrm{As}(\mathrm{V})$ reductases. It has been shown that $\mathrm{As}(\mathrm{V})$ reductases in mammalian cells catalyze the reduction of $\mathrm{As}(\mathrm{V})$ to $\mathrm{As}(\mathrm{III})$ (Radabaugh \& Aposhian 2000). These enzymes are functionally homologous to the $\mathrm{ArsC}$ protein of the bacterial ars operon that reduces $\mathrm{As}(\mathrm{V})$ to As(III) (Oden et al. 1994). Interestingly, As(V) reductases homolog was not being identified in the C. elegans genome. Therefore, GSH-mediated reduction of $\mathrm{As}(\mathrm{V})$ may predominate in C. elegans although the detailed mechanisms remain to be elucidated.

To investigate the ability of $C$. elegans to withstand the arsenic-induced toxicity, wild-type and gcs- 1 mutant nematodes were exposed to a range of $\mathrm{As}(\mathrm{III})$ and $\mathrm{As}(\mathrm{V})$ ion concentrations and the dead worms were scored over a $24 \mathrm{~h}$ period. The survival rates of worms to arsenic were dose dependent
(Figures 2a and 3a). These dose-dependent decreases of cellular survival rates were directly correlated with the wild-type and $g c s-1$ mutant strains of worms (Figures 2a and 3a). For wildtype worms, the survival rate did not show a significant decrease until exposure to 0.5 and $20 \mathrm{mM}$ $\mathrm{As}(\mathrm{III})$ and $\mathrm{As}(\mathrm{V})$, respectively. In contrast, the survival rate of $g c s-1$ mutant was significantly decreased after exposure to 0.025 and $1.5 \mathrm{mM}$ $\mathrm{As}(\mathrm{III})$ and $\mathrm{As}(\mathrm{V})$, respectively. This suggests that at low arsenic exposures glutathione biosynthesis via regulation of $g c s-1$ provides a protective mechanism against arsenic toxicity. While other defense systems or enzymes, such as catalase and superoxide dismutase (SOD), may still be available to protect the cells from arsenic toxicity, our data still support the concept that intracellular GSH status is critical for the survival rate of C. elegans when subjected to arsenic exposure. In contrast, when worms are exposed to higher concentrations of arsenic, the oxidative stress induced by high concentrations might overwhelm or inhibit the antioxidative systems, including glutathione biosynthesis. Furthermore, glutathione related enzyme activities, including glutathione reductase (GR) and glutathione $S$-transferase (GST) (Schuliga et al. 2002), have been shown to be affected by As(III). Therefore, it is possible that in C. elegans, arsenic exposure affects intracellular GSH status via regulations of intracellular glutathione biosynthesis and its related enzymes. 
The $\mathrm{LC}_{50}$ values of worms for $\mathrm{As}(\mathrm{III})$ and $\mathrm{As}(\mathrm{V})$ were established. For As(III), the As(III) $\mathrm{LC}_{50}$ value for the wild-type $(1.282 \pm 0.306 \mathrm{mM})$ compares well with the other report (Williams \& Dusenbery 1990). Additionally, the As(III) LC $_{50}$ value for the wild-type $(1.282 \pm 0.306 \mathrm{mM})$ was significantly $(P<0.01)$ higher than the value for the $g c s-1$ mutant $(0.085 \pm 0.019 \mathrm{mM})$ (Figure $2 \mathrm{~b}$ ). When As(III) concentration was increased to $0.025 \mathrm{mM}$, the survival rate of $g c s-1$ mutant was significantly decreased. This observation indicates that following the reduction of activity of the intracellular GSH system, the animals became increasingly vulnerable to As(III) exposure, even at As(III) concentrations as low as $0.025 \mathrm{mM}$. Similarly, for $\mathrm{As}(\mathrm{V})$, the $\mathrm{As}(\mathrm{V}) \mathrm{LC}_{50}$ value for $g c s$ 1 mutant $(2.780 \pm 0.563 \mathrm{mM})$ was significantly $(P<0.001)$ different from the wild-type $(34.54 \pm$ $3.261 \mathrm{mM}$ ) (Figure 3b). Thus, our findings suggest that intracellular GSH plays a critical role in protecting C. elegans from arsenic toxicity.

The toxic effect of arsenic exposure time to $C$. elegans was investigated. Both As(III) and $\mathrm{As}(\mathrm{V})$ induced toxicity on wild-type and $g c s-1$ mutant worms showed time-dependence. For both $\mathrm{As}(\mathrm{III})$ and $\mathrm{As}(\mathrm{V})$, gcs-1 mutant worms appeared to be more sensitive to arsenic toxicity than that of wild-type (Figure 4). When gcs-1 mutant worms were exposed to an arsenic $\mathrm{LC}_{50}$ value, the survival rate of worms began to significantly decrease after $4 \mathrm{~h}$ exposure. In contrast, when wild-type worms were exposed to the corresponding $\mathrm{LC}_{50}$ value, the animals did not show a significant decrease of survival rate until $12 \mathrm{~h}$ arsenic exposure (Figure 4). This observation indicates that the reduction of intracellular GSH in the $g c s-1$ mutant made the worms increasingly vulnerable to arsenic exposure. Additionally, the reduction of GSH in the $g c s-1$ mutant might also affect the biosynthesis or activities of glutathione-related enzymes and consequently that resulted in a dramatic increase in sensitivity against arsenic toxicity in the mutant worms.

In conclusion, we have shown that GCS-1 is essential for the synthesis of intracellular GSH in C. elegans and that consequently intracellular GSH status plays a critical role in protection of C. elegans from arsenic-induced toxicity. The exact mechanism(s) of cellular and molecular events associated with arsenic toxicity are poorly understood. In this study, we show that arsenic exerts its toxicity through the generation of reactive oxygen species (ROS) and oxidative stress. However, many possible modes of arsenic action may also contribute in part the observed toxicity. These include chromosomal abnormalities (Nakamuro \& Sayato 1981), altered DNA repair and DNA methylation patterns (Kitchin 2001), altered cell proliferation (Barrett et al. 1989), abnormal gene amplification (Goering et al. 1999), and inhibition of p53 (Hamadeh et al. 1999) and telomerase (Chou et al. 2001). It has been shown that exposure of lung epithelial cells to $5 \mu \mathrm{M}$ As(III) results in an increase in $\gamma$-GCS (Li et al. 2002) expression. In C. elegans, in order to maintain redox homeostasis in the cells and to cope with the excess of ROS produced during the arsenic-mediate oxidative stress, $g c s-1$ gene expression may be activated. Although the present work show interesting insights into mechanisms of arsenic toxicity using C. elegans model, the molecular mechanisms by which the arsenic-induced gene regulation and expression will require further investigation.

\section{References}

Abernathy CO, Liu YP, Longfellow D, Aposhian HV, Beck B, Fowler B, Goyer R, Menzer R, Rossman T, Thompson C, Waalkes M. 1999 Arsenic: health effects, mechanisms of actions, and research issues. Environ Health Perspect 107, 593-597.

An JH, Blackwell TK. 2003 SKN-1 links C. elegans mesendodermal specification to a conserved oxidative stress response. Genes Dev 17, 1882-1893.

Agency for Toxic Substances and Disease Registry. 2000 Toxicological profile for arsenic (PB/2000/108021). U.S. Department of Health and Human Services, Public Health Service: Washington, DC.

Barrett JC, Lamb PW, Wang TC, Lee TC. 1989 Mechanisms of arsenic-induced cell transformation. Biol Trace Elem Res 21, 421-429.

Brenner S. 1974 The genetics of Caenorhabditis elegans. Genetics 77, 71-94.

Broeks A, Gerrard B, Allikmets R, Dean M, Plasterk RH. 1996 Homologues of the human multidrug resistance genes MRP and MDR contribute to heavy metal resistance in the soil nematode Caenorhabditis elegans. EMBO J 15, 6132-6143.

Canesi L, Ciacci C, Piccoli G, Stocchi V, Viarengo A, Gallo G. 1998 In vitro and in vivo effects of heavy metals on mussel digestive gland hexokinase activity: the role of glutathione. Comp Biochem Physiol 120, 261-268.

Cavigelli M, Li WW, Lin A, Su B, Yoshioka K, Karin M. 1996 The tumor promoter arsenite stimulates AP-1 activity by inhibiting a JNK phosphatase. EMBO J 15, 6269-6279.

Chou WC, Hawkins AL, Barrett JF, Griffin CA, Dang CV. 2001 Arsenic inhibition of telomerase transcription leads to genetic instability. J Clin Invest 108, 1541-1547.

Dai J, Weinberg RS, Waxman S, Jing Y. 1999 Malignant cells can be sensitized to undergo growth inhibition and apoptosis 
by arsenic trioxide through modulation of the glutathione redox system. Blood 93, 268-277.

Del Razo LM, Styblo M, Cullen WR, Thomas DJ. 2001 Determination of trivalent methylated arsenicals in biological matrices. Toxicol Appl Pharmacol 174, 282-293.

Delnomdedieu M, Basti MM, Otvos JO, Thomas DJ. 1993 Transfer of arsenite from glutathione to dithiol: a model of interaction. Chem Res Toxicol 6, 598-602.

Delnomdedieu M, Basti MM, Styblo M, Otvos JD, Thomas DJ. 1994 Complexation of arsenic species in rabbit erythrocytes. Chem Res Toxicol 7, 621-627.

Dudley E, Klaassen CD. 1984 Changes in hepatic glutathione concentration modify cadmium-induced hepatotoxicity. Toxicol Appl Pharmacol 72, 530-538.

Eaton L, Stacey NH, Wong KL, Klaassen CD. 1980 Doseresponse effects of various metal ions on rat liver, metallothionein, glutathione, heme oxygenase and cytochrome P450. Toxicol Appl Pharmacol 55, 393-402.

Kawasaki M, Hisamoto N, Iino Y, Yamamoto M, NinomiyaTsuji J, Matsumoto K. 1999 A Caenorhabditis elegans JNK signal transduction pathway regulates coordinated movement via type-D GABAergic motor neurons. EMBO J $\mathbf{1 8}$, 3604-3615.

Freedman JH, Slice LW, Dixon D, Fire A, Rubin CS. 1993 The novel metallothionein genes of Caenorhabditis elegans. Structural organization and inducible, cell-specific expression. J Biol Chem 268, 2554-2564.

Giglio AM, Hunter T, Bannister JV, Bannister WH, Hunter G. 1994 The copper/zinc superoxide dismutase gene of $\mathrm{Ca}$ enorhabditis elegans. Biochem Mol Biol Int 33, 41-44.

Goering PL, Aposhian HV, Mass MJ, Cebrian M, Beck BD, Waalkes MP. 1999 The enigma of arsenic carcinogenesis: role of metabolism. Toxicol Sci 49, 5-14.

Hamadeh HK, Vargas M, Lee E, Menzel DB. 1999 Arsenic disrupts cellular levels of $\mathrm{p} 53$ and mdm2: a potential mechanism of carcinogenesis. Biochem Biophys Res Commun 263, 446-449.

Hayes JD, McLellan LI. 1999 Glutathione and glutathionedependent enzymes represent a co-ordinately regulated defence against oxidative stress. Free Radic Res. 31, 273-300.

Hayes JD, McMahon M. 2001 Molecular basis for the contribution of the antioxidant responsive element to cancer chemoprevention. Cancer Lett 174, 103-113.

Heschl MF, Baillie DL. 1990 The HSP70 multigene family of Caenorhabditis elegans. Comp Biochem Physiol 96, 633-637.

Hirata M, Tanaka A, Hisanaga A, Ishinishi N. 1990 Effects of glutathione depletion on the acute nephrotoxic potential of arsenite and on arsenic metabolism in hamsters. Toxicol Appl Pharmacol 106, 469-481.

Hope IA. 1999 C. elegans: A Practical Approach. Oxford: Oxford University Press, UK: 62-63.

Huang H, Huang CF, Wu DR, Jinn CM, Jan KY. 1993 Glutathione as a cellular defense against arsenite toxicity in cultured Chinese hamster ovary cells. Toxicology 79, 195204

Kitchin KT. 2001 Recent advances in arsenic carcinogenesis: modes of action, animal model systems, and methylated arsenic metabolites. Toxicol Appl Pharmacol 172, 249-261.

Land M, Islas-Trejo A, Rubin CS. 1994 Structure and expression of a novel, neuronal protein kinase $\mathrm{C}$ (PKC1B) from Caenorhabditis elegans. PKC1B is expressed selectively in neurons that receive, transmit, and process environmental signals. J Biol Chem 269, 14820-14827.
Lerman SA, Clarkson TW, Gerson RJ. 1983 Arsenic uptake and metabolism by liver cells is dependent on arsenic oxidation state. Chem Biol Interact 45, 401-406.

Li M, Cai JF, Chiu JF. 2002 Arsenic induces oxidative stress and activates stress gene expressions in cultured lung epithelial cells. $J$ Cell Biochem 87, 29-38.

Liao VH, Freedman JH. 2002 Differential display analysis of gene expression in invertebrates. Cell Mol Life Sci 59, 1256 1263.

Liao VH, Dong J, Freedman JH. 2002 Molecular characterization of a novel, cadmium-inducible gene from the nematode Caenorhabditis elegans. A new gene that contributes to the resistance to cadmium toxicity. J Biol Chem 277, 42049-42059.

Liao VH, Freedman JH. 2001 Characterization of a cadmiuminducible isoform of pyruvate carboxylase from Caenorhabditis elegans. DNA Seq 12, 137-145.

Liao VH, Freedman JH. 1998 Cadmium-regulated genes from the nematode Caenorhabditis elegans. Identification and cloning of new cadmium-responsive genes by differential display. J Biol Chem 273, 31962-31970.

Meister A, Anderson ME. 1983 Glutathione. Аnпu Rev Biochem 52, 711-760.

Nakamuro K, Sayato Y. 1981 Comparative studies of chromosomal aberration induced by trivalent and pentavalent arsenic. Mutat Res 88, 73-80.

NRC. 1999 Arsenic in Drinking Water. Washington, DC: National Research Council.

Ochi T. 1997 Arsenic compound-induced increases in glutathione levels in cultured Chinese hamster V79 cells and mechanisms associated with changes in gamma-glutamylcysteine synthetase activity, cystine uptake and utilization of cysteine. Arch Toxicol 71, 730-740.

Ochi T, Kaise T, Oya-Ohta Y. 1994 Glutathione plays different roles in the induction of the cytotoxic effects of inorganic and organic arsenic compounds in cultured BALB/c 3T3 cells. Experientia 50, 115-120.

Oden KL, Gladysheva TB, Rosen BP. 1994 Arsenate reduction mediated by the plasmid-encoded ArsC protein is coupled to glutathione. Mol Microbiol 12, 301-306.

Oya-Ohta Y, Kaise T, Ochi T. 1996 Induction of chromosomal aberrations in cultured human fibroblasts by inorganic and organic arsenic compounds and the different roles of glutathione in such induction. Mutat Res 357, 123-129.

Pompella A, Visvikis A, Paolicchi A, De Tata V, Casini AF. 2003 The changing faces of glutathione, a cellular protagonist. Biochem Pharmacol 66, 1499-1503.

Radabaugh TR, Aposhian HV. 2000 Enzymatic reduction of arsenic compounds in mammalian systems: reduction of arsenate to arsenite by human liver arsenate reductase. Chem Res Toxicol 13, 26-30.

Richman PG, Meister A. 1975 Regulation of gamma-glutamylcysteine synthetase by nonallosteric feedback inhibition by glutathione. J Biol Chem 250, 1422-1426.

Sampayo JN, Olsen A, Lithgow GJ. 2003 Oxidative stress in Caenorhabditis elegans: protective effects of superoxide dismutase/catalase mimetics. Aging Cell 2, 319-326.

Schuliga M, Chouchane S, Snow ET. 2002 Upregulation of glutathione-related genes and enzyme activities in cultured human cells by sublethal concentrations of inorganic arsenic. Toxicol Sci 70, 183-192.

Scott N, Hatlelid KM, MacKenzie NE, Carter DE. 1993 Reaction of arsenic(III) and arsenic(V) species with glutathione. Chem Res Toxicol 6, 102-106. 
Shimizu M, Hochadel JF, Fulmer BA, Waalkes MP. 1998 Effect of glutathione depletion and metallothionein gene expression on arsenic-induced cytotoxicity and c-myc expression in vitro. Toxicol Sci 45, 204-211.

Stringham EG, Jones D, Candido EP. 1992 Expression of the polyubiquitin-encoding gene (ubq-1) in transgenic Caenorhabditis elegans. Gene 113, 165-173.

Tawe WN, Eschbach ML, Walter RD, Henkle-Duhrsen K. 1998 Identification of stress-responsive genes in Caenor- habditis elegans using RT-PCR differential display. Nucleic Acids Res 26, 1621-1627.

Tchounwou PB, Wilson BA, Ishaque A. 1999 Important considerations in the development of public health advisories for arsenic and arsenic containing compounds in drinking water. Rev Environ Health 14, 1-19.

Williams PL, Dusenbery DB. 1990 Aquatic toxicity testing using the nematode Caenorhabditis elegans. Environ Toxicol Chem 9, 1285-1290. 